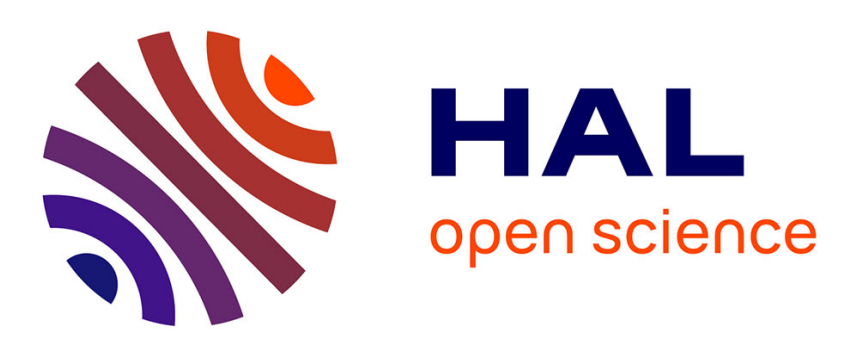

\title{
Reaction mechanism in the mechanochemical synthesis of dibenzophenazine: application of vibronic coupling density analysis
}

\author{
Naoki Haruta, Tohru Sato, Kazuyoshi Tanaka, Michel Baron
}

\section{To cite this version:}

Naoki Haruta, Tohru Sato, Kazuyoshi Tanaka, Michel Baron. Reaction mechanism in the mechanochemical synthesis of dibenzophenazine: application of vibronic coupling density analysis. Tetrahedron Letters, 2013, 54 (44), pp.5920-5923. 10.1016/j.tetlet.2013.08.114 . hal-01632791

\author{
HAL Id: hal-01632791 \\ https://hal.science/hal-01632791
}

Submitted on 24 Feb 2021

HAL is a multi-disciplinary open access archive for the deposit and dissemination of scientific research documents, whether they are published or not. The documents may come from teaching and research institutions in France or abroad, or from public or private research centers.
L'archive ouverte pluridisciplinaire HAL, est destinée au dépôt et à la diffusion de documents scientifiques de niveau recherche, publiés ou non, émanant des établissements d'enseignement et de recherche français ou étrangers, des laboratoires publics ou privés. 


\title{
Reaction mechanism in the mechanochemical synthesis of dibenzophenazine: application of vibronic coupling density analysis
}

\author{
Naoki Haruta ${ }^{a}$, Tohru Sato ${ }^{\mathrm{a}, \mathrm{b}, *}$, Kazuyoshi Tanaka ${ }^{\mathrm{a}}$, Michel Baron ${ }^{\mathrm{c}}$ \\ a Department of Molecular Engineering, Graduate School of Engineering, Kyoto University, Nishikyo-ku, Kyoto 615-8510, Japan \\ ${ }^{\mathrm{b}}$ Unit of Elements Strategy Initiative for Catalysts \& Batteries, Kyoto University, Nishikyo-ku, Kyoto 615-8510, Japan \\ ${ }^{\mathrm{C}}$ Université de Toulouse, Mines-Albi, CNRS UMR 5302, Centre Rapsodee, Campus Jarlard, 81013 Albi Cedex 09, France
}

\begin{abstract}
A B S T R A C T
The reaction mechanism for mechanochemical synthesis of dibenzophenazine was theoretically investigated in terms of the vibronic coupling density, which describes the interactions between electrons and nuclear motions. The concept theoretically indicates experimentally observed reactive sites that cannot be explained by the conventional frontier orbital theory. The results of vibronic coupling density analysis suggested the difference between reaction mechanisms under thermal and mechanochemical conditions.
\end{abstract}

Keywords:

Mechanochemistry

Dibenzophenazine

Vibronic coupling

Vibronic coupling density

Frontier orbital theory

\section{Introduction}

Mechanochemistry has received a great deal of attention because it is a green synthesis method without organic solvents. ${ }^{1,2}$ Many organic compounds have been synthesized mechanochemically. Dibenzo[ $a, c]$ phenazine, which has a similar quinoxaline structure to pharmacologically active compounds ${ }^{3}$ and organic semiconductors, ${ }^{4,5}$ was recently synthesized from $o$-phenylenediamine and phenanthrene-9,10-dione by a mechanochemical ballmilling method (Fig. 1). ${ }^{6}$ Although a reaction mechanism based on the concepts of organic chemistry has been proposed, ${ }^{7}$ the mechanism has not been elucidated using quantum chemistry calculations.

Observed reactive sites of mechanochemical reactions are not always consistent with the Woodward-Hoffmann rules8 or frontier orbital theory. ${ }^{9,10}$ Mechanochemical conditions can induce special excited states due to unexpected phenomena as inverse Jahn-Teller effect. ${ }^{11,12}$ These excited states sometimes allow the formation of products unexpected by classical rules as Woodward-Hoffmann rules. $^{13}$ In the present case, since the highest occupied molecular orbital (HOMO) level of a diamine is high and the lowest unoccupied molecular orbital (LUMO) level of a dione is low (see Supplementary data), they can be regarded

\footnotetext{
* Corresponding author. Tel.: +81 75383 2803; fax: +81 753832556

E-mail address: tsato@moleng.kyoto-u.ac.jp (T. Sato).
}

as an electron donor and electron acceptor, respectively. According to frontier orbital theory, reactive sites are indicated by large frontier orbital densities for the HOMO of the diamine and LUMO of the dione. As shown in Figure 2, the reactive sites are not so clear because of the delocalizations of the frontier orbitals. However, a closer look shows that the frontier orbital theory predicts the concerted formation of $\mathrm{C}-\mathrm{N}$ bonds between reactants since both the diamine and dione have almost the same symmetry for the orbital phase at their experimental reactive sites: $\mathrm{H}_{2} \mathrm{~N}-\mathrm{C}-\mathrm{C}-\mathrm{NH}_{2}$ for the diamine and $\mathrm{O}=\mathrm{C}-\mathrm{C}=\mathrm{O}$ for the dione. Note that the diamine shown in Figure 2(a) has the most stable structure with $C_{2}$ symmetry and not $C_{s}$ symmetry. This prediction is inconsistent with the stepwise formation proposed previously. ${ }^{7}$ The question of which mechanism is correct therefore arises. This question is important to understand its reaction profile and chemical kinetics.

To solve this question and overcome the difficulty in the frontier orbital theory, we applied vibronic coupling density (VCD) analy$\operatorname{sis}^{14,15}$ to the mechanochemical reaction. VCD describes the interactions between electrons and nuclear motions in density form just like frontier orbital density. VCD can be regarded as an extension of frontier orbital theory in the following respects: (1) stabilization in the initial stage of the reaction is considered, which is the same as in frontier orbital theory; (2) stabilization is due to the interaction between electrons and vibrations in VCD, which is completely ignored in frontier orbital theory; (3) electron correlation beyond orbital approximation can be included in VCD. The 


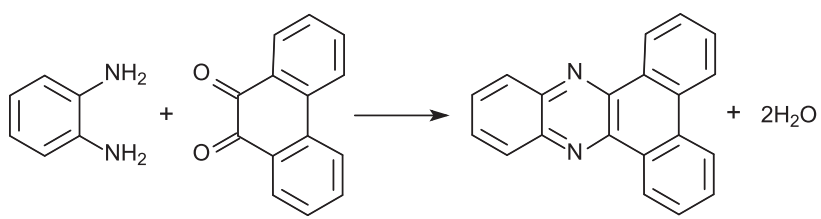

Figure 1. Reaction scheme for mechanochemical synthesis of dibenzo[a,c]phenazine from $o$-phenylenediamine and phenanthrene-9,10-dione. (a)

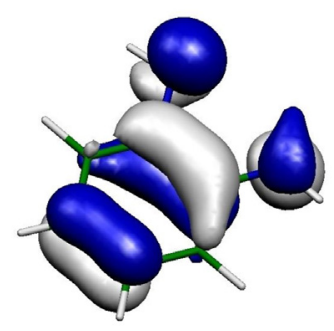

(b)

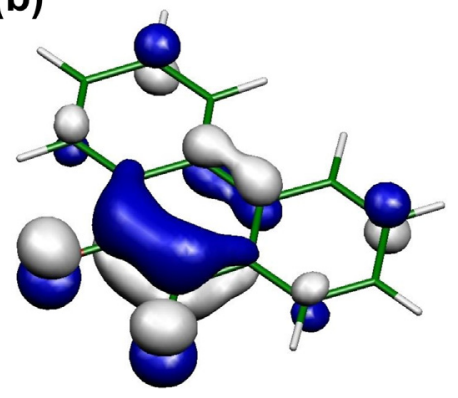

Figure 2. HOMO of the diamine and LUMO of the dione obtained by RB3LYP/6 $311 \mathrm{G}(\mathrm{d}, \mathrm{p})$ calculations. The isosurface values are $5.0 \times 10^{-2}$ a.u.

advantage of VCD is that it is independent of orbital approximation: in other words, it is approximation-invariant. This concept was successfully applied to explain the reactivity of fullerenes ${ }^{16-18}$ and other aromatic compounds ${ }^{14,15,19}$ where reactive sites sometimes cannot be clarified based on frontier orbital theory.

Note that we focused on the first step of the dibenzophenazine synthesis, that is, the $\mathrm{C}-\mathrm{N}$ bond formations between diamine and dione because only this step needs the approach and contact of the reactive centers of both reagents. Water eliminations are internal reactions following the first step.

\section{Theory}

In a chemical reaction, charge-transfer interaction (frontier orbital interaction) occurs between reactants as they approach each other. The charge transfer induces molecular vibrations via vibronic (vibration-electron) interaction, ${ }^{20,21}$ which triggers molecular deformations: bond cleavage and bond formation. Vibronic coupling is therefore the key concept to directly understanding the origin of the reaction.

The strength of vibronic coupling is estimated by the vibronic coupling constant (VCC) $V_{\alpha}$ :

$V_{\alpha}=\int d \tau \Psi_{\mathrm{CT}}^{*}\left(\frac{\partial \widehat{H}}{\partial Q_{\alpha}}\right)_{\mathbf{R}_{0}} \Psi_{\mathrm{CT}}$,

where $\widehat{H}$ is a molecular Hamiltonian, $\Psi_{\mathrm{CT}}$ is the electronic wave function after the charge transfer, $Q_{\alpha}$ is the vibrational coordinate of mode $\alpha, \mathbf{R}_{\mathbf{0}}$ is the molecular geometry before the charge transfer, (a)

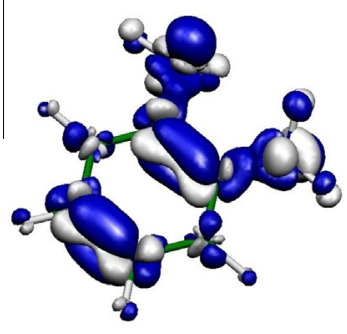

(b)

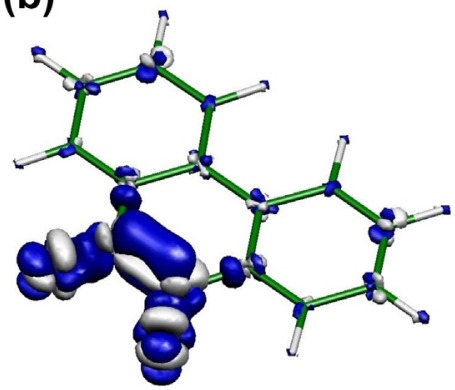

Figure 4. Vibronic coupling densities (VCDs) for effective modes: (a) $C_{2}$ symmetrical diamine cation and (b) dione anion. The isosurface values are $2.0 \times 10^{-5}$ a.u. Blue and gray surfaces are negative and positive contributions, respectively.

and $\tau$ denotes all spatial and spin coordinates of electrons. If $V_{\alpha}$ is not zero, molecular deformation along the normal mode $\alpha$ is induced so that molecular deformation mode $s$, which is a linear combination of the vibrational normal modes, occurs. In this Letter, we define the direction of the vibrational mode $\alpha$ such that $V_{\alpha}$ is negative. This means that the positive displacement of mode $\alpha$ induces stabilization in the charge-transfer state.

$V_{\alpha}$ can be written in density form using vibronic coupling density (VCD) $\eta_{\alpha}(\mathbf{r}):^{14,15}$

$V_{\alpha}=\int d^{3} \mathbf{r} \eta_{\alpha}(\mathbf{r})$

$\eta_{\alpha}(\mathbf{r})=\Delta \rho(\mathbf{r}) \times v_{\alpha}(\mathbf{r})$,

where $\Delta \rho(\mathbf{r})$ is the electron density change caused by the charge transfer and $v_{\alpha}(\mathbf{r})$ is the derivative of the potential acting on a single electron from all nuclei with respect to the normal coordinate $Q_{\alpha}$ at reference geometry $\mathbf{R}_{\mathbf{0}} . \Delta \rho(\mathbf{r})$ and $v_{\alpha}(\mathbf{r})$ can be obtained from electronic and vibrational structure calculations, respectively.

In the reactivity problem of a chemical reaction, we regard the effective vibrational mode, or deformation mode $s$, as the reaction mode. ${ }^{14-18}$ The effective vibrational coordinate $Q_{s}$ is defined as

$Q_{s}=\sum_{\alpha} \frac{V_{\alpha}}{\sqrt{\sum_{\alpha^{\prime}}\left|V_{\alpha^{\prime}}\right|^{2}}} Q_{\alpha}$,

which can be assumed to coincide with the steepest descent path in the early stage of a reaction. Because $\eta_{s}(\mathbf{r})$ gives a local picture of $V_{s}$, which is the origin of bond cleavage and bond formation, $\eta_{s}(\mathbf{r})$ can be regarded as a reactivity index. ${ }^{14-18}$

$\Delta \rho(\mathbf{r})$, which is the part of $\eta_{s}(\mathbf{r})$, is roughly equal to the frontier orbital density. It includes effects from the other orbitals due to orbital relaxation and orbital mixing effects, which are ignored in frontier orbital theory. In addition, the effects of nuclear motions (vibrational effects) are also included as $v_{s}(\mathbf{r})$, which is the part of $\eta_{s}(\mathbf{r})$. The distribution of VCD $\eta_{s}(\mathbf{r})$ tells us the region where stabilization due to vibronic coupling is large based on the electronic structure $\Delta \rho(\mathbf{r})$ and vibrational structure $v_{s}(\mathbf{r})$. Such a region can be regarded as a reactive site.

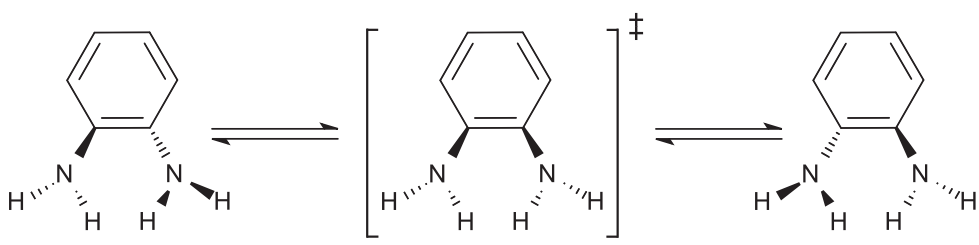

Figure 3. Two types of diamine structures: (left, right) $C_{2}$ symmetrical isomers, (center) $C_{s}$ symmetrical one. 
(a)

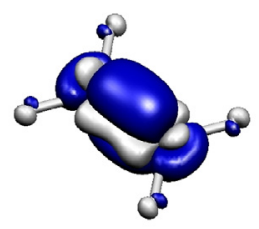

(b)

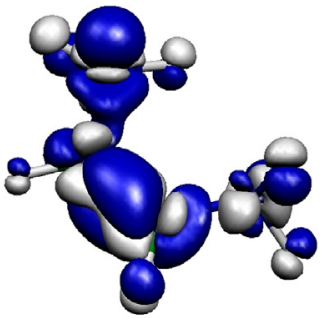

(c)

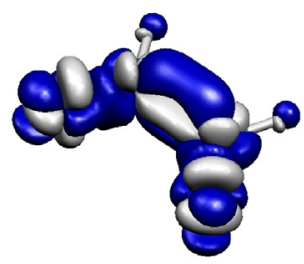

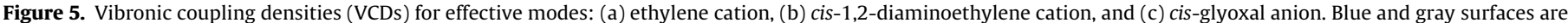
negative and positive contributions, respectively.

\section{Computational method}

Because the diamine is an electron donor and the dione is an electron acceptor (see Supplementary data), their charge-transfer states can be regarded as cationic and anionic ones, respectively. We therefore performed vibronic coupling density (VCD) analyses for the isolated diamine cation and isolated dione anion.

First, we optimized the neutral diamine and neutral dione with B3LYP/6-311G $(d, p)$ level of theory and performed vibrational analyses for the neutral species. Second, we calculated the electronic states of the diamine cation and dione anion at their neutral optimized geometries and calculated their potential energy gradients analytically. These calculations were performed by GAUSSIAN 03 Rev E.01.22

We used the potential energy gradients to evaluate vibronic coupling constants (VCCs) defined by Eq. (1) as per the HellmannFeynman theorem. ${ }^{23,24}$ From the electronic and vibrational states obtained above, we calculated VCDs defined by Eq. (3) for the diamine cation and dione anion. These calculations were performed with our codes.

\section{Results and discussion}

We obtained two types of diamine isomers: $C_{2}$ and $C_{s}$ symmetrical structures (Fig. 3). The $C_{2}$ symmetrical isomer had the most stable structure: the total electronic energy was lower than the $C_{s}$ symmetrical isomer by $182 \mathrm{meV}(4.20 \mathrm{kcal} / \mathrm{mol})$. Although the $C_{2}$ symmetrical isomer had no imaginary frequency, the $C_{s}$ symmetrical isomer had an imaginary one. We also obtained the $C_{2 v}$ symmetrical dione, which was the most stable and had no imaginary frequency. We therefore performed vibronic coupling density (VCD) analyses for the $C_{2}$ and $C_{s}$ symmetrical diamine cations and $C_{2 v}$ symmetrical dione anion.

Figures 4(a) and (b) show the VCDs for the effective modes of the $C_{2}$ symmetrical diamine cation and dione anion, respectively.

(a)

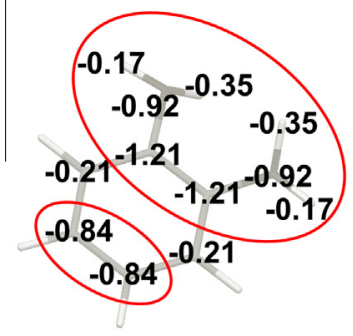

(b)

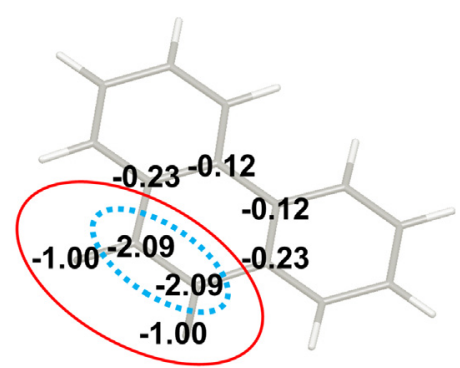

Figure 6. Atomic vibronic coupling constants (AVCCs) for effective modes in $10^{-4}$ a.u.: (a) $C_{2}$ symmetrical diamine cation and (b) dione anion. Constants for which absolute values were less than $0.10 \times 10^{-4}$ a.u. were ignored. Negative and positive values are stabilizing and destabilizing contributions, respectively.
The blue surfaces signify negative contribution: in other words, stabilizing contribution due to the vibronic coupling. From VCD analysis, we can extract a picture of a functional group. ${ }^{15}$ By comparing Figure 4 with Figure 5, we found that the diamine consists of two functional groups-ethylene and diaminoethylene-and the dione has one functional group-glyoxal. These sites can be considered to be reactive ones. Figures 6(a) and (b) show atomic vibronic coupling constants (AVCCs); ${ }^{15}$ these are the atomic contributions of the VCDs, which enable us to quantify the site reactivity. Figure 6(a) shows that the diaminoethylene fragment of the diamine was more reactive than the ethylene fragment because the diaminoethylene fragment had larger vibronic contributions; bond cleavage, and bond formation occurred more strongly. Figure 6(b) shows that the central $\mathrm{C}-\mathrm{C}$ bond of the glyoxal fragment of the dione was reactive because the $\mathrm{C}-\mathrm{C}$ bond had a much larger vibronic contributions than the terminal oxygens. These reactive sites of the diamine and dione as predicted by the VCD analysis were completely consistent with the experimental findings (Fig. 1).

Next, we examined whether concerted or stepwise $\mathrm{C}-\mathrm{N}$ formations between the reactants proceed in this mechanochemical reaction. This problem is important to understand its reaction profile and chemical kinetics. As shown in Figure 4(b), the dione has the symmetrical distribution of the VCD at its reactive site, which favors the concerted mechanism. Therefore, the reactivity of the diamine controls whether the concerted or stepwise mechanism occurs.

As shown in Figure 4(a), the $C_{2}$ symmetrical diamine has positive and negative distributions of the VCD at amino groups over its molecular plane. This is because the $C_{2}$ symmetrical diamine has the effective mode of opposite directions at amino groups, as shown in Figure $7(\mathrm{a})$. This fact suggests that the $C_{2}$ symmetrical diamine favors the stepwise mechanism (Fig. 8).

On the other hand, the $C_{s}$ symmetrical diamine has the effective mode of the same direction at amino groups as shown in Figure 7 (b). In the case of the $C_{s}$ symmetrical diamine, therefore, we obtained negative distributions of the VCD at amino groups over its molecular plane as shown in Fig. 8 (right). This suggests that the $C_{s}$ symmetrical diamine favors the concerted mechanism (Fig. 8). (a)

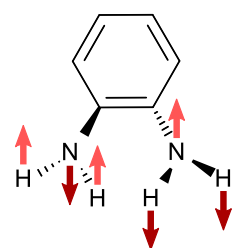

(b)

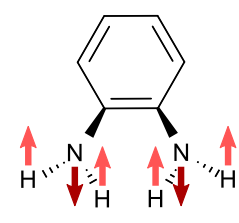

Figure 7. Displacements of amino groups in effective modes of diamine cations: (a) $C_{2}$ symmetrical structure, (b) $C_{s}$ symmetrical structure. 


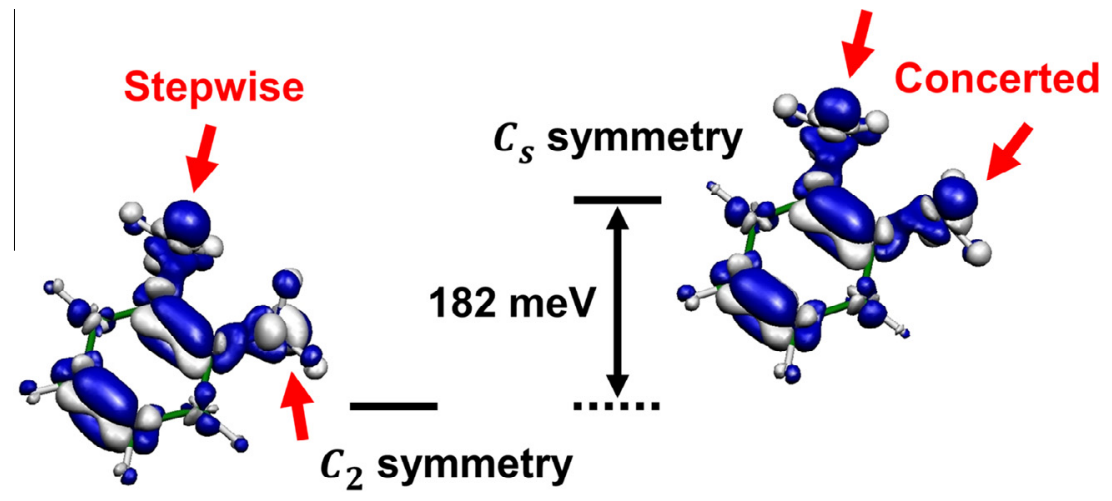

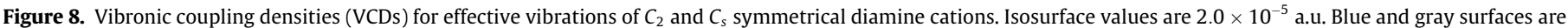
stabilizing and destabilizing contributions, respectively. Note that signs on VCD of amino groups differ in the $C_{2}$ structure and are the same in the $C_{s}$ structure.

Because the $C_{s}$ symmetrical diamine was less stable than the $C_{2}$ symmetrical diamine by $182 \mathrm{meV}(4.20 \mathrm{kcal} / \mathrm{mol})$, the concerted mechanism is preferred thermally. However, mechanochemical techniques such as the ball-milling method could give enough energy for some diamine molecules to overwhelm the energy difference between the $C_{2}$ and $C_{s}$ structures. The concerted mechanism therefore can proceed mechanochemically via the activated species: the $C_{s}$ symmetrical diamine. The greater possibility of the concerted mechanism represents the uniqueness of the mechanochemical reaction.

A thermal condition prefers the stepwise $\mathrm{C}-\mathrm{N}$ formations, while a mechanochemical condition can enhance the concerted reaction. This difference in chemical reactivity cannot be predicted by frontier orbital theory because the direction of displacement of the nitrogen atoms in the effective mode is essential for this argument (Fig. 7).

\section{Conclusion}

We elucidated the reaction mechanism for mechanochemical synthesis of dibenzo[ $a, c]$ phenazine by using vibronic coupling density analysis. Our method clearly explains the reactive sites of the reactants 0 -phenylenediamine and phenanthrene-9,10-dione. Our results suggest that the $C_{2}$ symmetrical isomer of the diamine, which is the most stable isomer, favors the stepwise mechanism, while the $C_{s}$ symmetrical isomer, which is energetically unstable but mechanochemically possible, favors the concerted mechanism. Therefore, although the stepwise mechanism is preferred under the thermal condition, the concerted one can be enhanced under the mechanochemical condition. This reactivity difference can be related to the uniqueness of the mechanochemical reaction.

\section{Acknowledgments}

This research was supported by JSPS-CNRS Bilateral Research grant. Numerical calculations were partly performed at the Supercomputer Laboratory of the Kyoto University and the Research Center for Computational Science, Okazaki, Japan.

\section{Appendix A. Supplementary data}

Supplementary data associated with this article can be found, in the online version, at http://dx.doi.org/10.1016/j.tetlet.2013.08. 114.

\section{References}

1. Baron, M. Waste Biomass Valorization 2012, 3, 395-407.

2. Wang, G.-W. Chem. Soc. Rev. 2013, 42, 7668-7700.

3. Sakata, G.; Makino, K.; Kurasawa, Y. Heterocycles 1988, 27, 2481-2515.

4. Dailey, S.; Feast, W. J.; Peace, R. J.; Sage, I. C.; Till, S.; Wood, E. L. J. Mater. Chem. 2001, 11, 2238-2243.

5. O’Brien, D.; Weaver, M. S.; Lidzey, D. G.; Bradley, D. D. C. Appl. Phys. Lett. 1996, 69, 881-883.

6. Carlier, L.; Baron, M.; Chamayou, A.; Couarraze, G. Tetrahedron Lett. 2011, 52, 4686-4689.

7. Carlier, L.; Baron, M.; Chamayou, A.; Couarraze, G. Powder Technol. 2013, 240, 41-47.

8. Woodward, R. B.; Hoffmann, R. Angew. Chem., Int. Ed. Engl. 1969, 8, 781-853.

9. Fukui, K.; Yonezawa, T.; Shingu, H. J. Chem. Phys. 1952, 20, 722-725.

10. Fukui, K. Acc. Chem. Res. 1971, 4, 57-64.

11. Gilman, J. J. Science 1996, 274, 65.

12. Luty, T.; Ordon, P.; Eckhardt, C. J. J. Chem. Phys. 2002, 117, 1775-1785.

13. Hickenboth, C. R.; Moore, J. S.; White, S. R.; Sottos, N. R.; Baudry, J.; Wilson, S. R. Nature 2007, 446, 423-427.

14. Sato, T.; Tokunaga, K.; Tanaka, K. J. Phys. Chem. A 2008, 112, 758-767.

15. T.Sato, K.Tokunaga, N.Iwahara, K.Shizu and K.Tanaka, In: The Jahn-Teller Effect: Fundamentals and Implications for Physics and Chemistry (Springer Series in Chemical Physics 97), ed., H. Köppel, D. R. Yarkony and H.Barentzen, 2009, Springer-Verlag; Berlin Heidelberg, pp 99-129.

16. Sato, T.; Iwahara, N.; Haruta, N.; Tanaka, K. Chem. Phys. Lett. 2012, 531, 257260.

17. Haruta, N.; Sato, T.; Tanaka, K. J. Org. Chem. 2012, 77, 9702-9706.

18. Haruta, N.; Sato, T.; Iwahara, N.; Tanaka, K. J. Phys.: Conf. Ser. 2013, 428, 012003 1-012003 7 .

19. Sato, T.; Uejima, M.; Iwahara, N.; Haruta, N.; Shizu, K.; Tanaka, K. J. Phys.: Conf. Ser. 2013, 428, $0120101-01201019$.

20. Fischer, G. Vibronic Coupling: The Interaction between the Electronic and Nuclear Motions; Academic Press: London, 1984.

21. Bersuker, I. B.; Polinger, V. Z. Vibronic Interactions in Molecules and Crystals; Springer-Verlag: New York, 1989.

22. Frisch, M. J.; Trucks, G. W.; Schlegel, H. B.; Scuseria, G. E.; Robb, M. A.; Cheeseman, J. R.; Montgomery, J. A, Jr.; Vreven, T.; Kudin, K. N.; Burant, J. C.; Millam, J. M.; Iyengar, S. S.; Tomasi, J.; Barone, V.; Mennucci, B.; Cossi, M.; Scalmani, G.; Rega, N.; Petersson, G. A.; Nakatsuji, H.; Hada, M.; Ehara, M.; Toyota, K.; Fukuda, R.; Hasegawa, J.; Ishida, M.; Nakajima, T.; Honda, Y.; Kitao, O.; Nakai, H.; Klene, M.; Li, X.; Knox, J. E.; Hratchian, H. P.; Cross, J. B.; Bakken, V.; Adamo, C.; Jaramillo, J.; Gomperts, R.; Stratmann, R. E.; Yazyev, O.; Austin, A. J.; Cammi, R.; Pomelli, C.; Ochterski, J. W.; Ayala, P. Y.; Morokuma, K.; Voth, G. A.; Salvador, P.; Dannenberg, J. J.; Zakrzewski, V. G.; Dapprich, S.; Daniels, A. D.; Strain, M. C.; Farkas, O.; Malick, D. K.; Rabuck, A. D.; Raghavachari, K.; Foresman, J. B.; Ortiz, J. V.; Cui, Q.; Baboul, A. G.; Clifford, S.; Cioslowski, J.; Stefanov, B. B.; Liu, G.; Liashenko, A.; Piskorz, P.; Komaromi, I.; Martin, R. L.; Fox, D. J.; Keith, T.; Al-Laham, M. A.; Peng, C. Y.; Nanayakkara, A.; Challacombe, M.; Gill, P. M. W.; Johnson, B.; Chen, W.; Wong, M. W.; Gonzalez, C.; Pople, J. A. GAUSSIAN 03, Revision E 01; Gaussian, Inc.: Wallingford, CT, 2004.

23. Hellmann, H. Einführung in die Quantenchemie; Deuticke and Company: Leipzig, 1937.

24. Feynman, R. P. Phys. Rev. 1939, 56, 340-343. 